\title{
Aesop's fables, the ant, the grasshopper, and prophylactic first-stage elephant trunk for moderately dilated descending aorta in patients with predominately proximal disease
}

\author{
Kevin L. Greason, MD
}

From the Division of Cardiovascular Surgery, Mayo Clinic, Rochester, Minn.

Disclosures: Author has nothing to disclose with regard to commercial support.

Received for publication Aug 30, 2015; accepted for publication Aug 31, 2015; available ahead of print Sept 26, 2015 .

Address for reprints: Kevin L. Greason, MD, Mayo Clinic, Rochester, MN 55905 (E-mail: greason.kevin@mayo. edu).

J Thorac Cardiovasc Surg 2015;150:1158-9

0022-5223/ $\$ 36.00$

Copyright (c) 2015 by The American Association for Thoracic Surgery

http://dx.doi.org/10.1016/j.jtcvs.2015.08.104

Moral of Aesop's fable of the ant and grasshopper: It is best to prepare for the days of necessity.

Readers of the Journal will find interest in the well-written article in this issue by Idrees and colleagues ${ }^{2}$ about prophylactic first-stage elephant trunk for moderately dilated descending aorta in patients with predominantly proximal disease. The essence of the article is that the prophylactic first operation is safe and prepares for the necessity of the expected second operation. As with most things surgical, patient selection is paramount, and that is the message that readers of the Journal should take away from this article.

Idrees and colleagues ${ }^{2}$ report their experience with 572 patients operated on with the first-stage elephant trunk procedure from 1992 to 2012 . The study group included a subset of 117 patients $(20.5 \%)$ with an age of $63 \pm 13$ years who had predominately ascending or arch pathology but who had only moderate dilation of the descending aorta $(4.0 \pm 0.6 \mathrm{~cm})$. This group of patients received a prophylactic elephant trunk on the basis of suspicion that they would require a distal intervention at a later stage. An operative mortality of $0.8 \%(1 / 117)$ is quite reassuring, but is that all of the story?

The first question to ask is whether the prophylactic elephant trunk results in a greater risk of stroke than a less aggressive procedure such as a hemiarch operation. Idrees and colleagues ${ }^{2}$ report that stroke occurred in 7 patients $(6 \%)$. It is likely, however, that few of these 7 patients would have been candidates for a hemiarch procedure anyway; 5 of them had extensive arch atheroma, and another had a pseudoaneurysm with thrombus at the distal anastomosis of a previous ascending aorta dissection repair. The increased stroke concern is probably more theoretical than practical, as evidenced by a study from the Mayo Clinic that reported similar rates of neurologic deficit in patients operated on with total $(6 \%)$ and hemiarch procedures $(7 \%) .{ }^{3}$

The most important concept to understand from this analysis may be found in the methods section under the heading

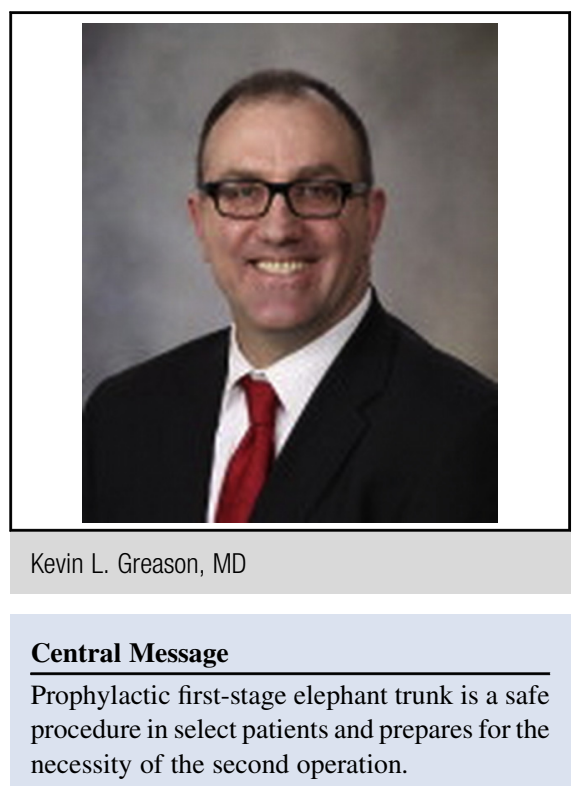

See Article page 1150 . of "Indications for Prophylactic ET." The reader must appreciate that this was a highly select group of patients who had a baseline condition placing them at increased risk for progressive degeneration of the descending aorta. Such conditions included chronic dissection, connective tissue disorders, and aortitis. Notwithstanding the presence of these conditions, Idrees and colleagues ${ }^{2}$ include the caveat that the decision to perform a more extended repair still requires surgical judgment.

As expected, there was frequent necessity for the secondstage procedure. Idrees and colleagues ${ }^{2}$ reported that 53 patients $(45 \%)$ underwent the second-stage elephant trunk procedure, a group that included 3 patients operated during the first-stage procedure hospital admission, 11 operated for an acute descending aorta event, and 34 operated within a year of the first-stage procedure. Additional follow-up of patients who have not received the second-stage procedure included 1 patient who died of a subsequent acute descending aorta dissection, 3 who were offered but refused the second stage-procedure, 6 who are currently in the queue for the second-stage procedure, and 8 who died of unknown cause. There is little doubt patients were at increased risk for progressive degeneration of the descending aorta. 
The final point to consider is that most, if not all, of these patients would have had inadequate descending aorta anatomy for subsequent endovascular elephant trunk completion had the first-stage procedure been anything other than an elephant trunk. The mean descending aortic diameter was less than $4 \mathrm{~cm}$ in only $42(36 \%)$ patients, and no mention is made of potential endograft landing zone anatomy in that group. The prophylactic first-stage elephant trunk procedure, on the other hand, provides an ideal landing zone for subsequent endovascular elephant trunk completion, which the majority of patients $(62 \%)$ received during the second-stage procedure.

The strength of this report lies in its well thought-out collection, analysis, and reporting of data. The main weakness is the lack of detail in the 8 deaths of unknown cause.
Knowing the etiologies could only have added to the strength of the study. Prophylactic first-stage elephant trunk is a safe and effective strategy for select patients at increased risk for progressive degeneration of the moderately dilated descending aorta. A successful procedure sets the stage for managing late descending aortic complications and disease progression.

\section{References}

1. Alchin L, ed. The ant and the grasshopper: an Aesop's fable. United Kingdom: Siteseen; 2015. Available at: http://www.taleswithmorals.com/aesop-fable-theant-and-the-grasshopper.htm. Accessed August 30, 2015.

2. Idrees JJ, Roselli EE, Wojnarski CM, Feng K, Aftab M, Johnston DR, et al. Prophylactic first stage elephant trunk for moderately dilated descending aorta in patients with predominantly proximal disease. J Thorac Cardiovasc Surg. July 30, 2015;150:1150-7

3. Thomas M, Li Z, Cook DJ, Greason KL, Sundt TM. Contemporary results of open aortic arch surgery. J Thorac Cardiovasc Surg. 2012;144:838-44. 